\title{
О.А. Синенко
}

\section{ПРАКТИКА ПРИМЕНЕНИЯ МЕХАНИЗМОВ РЕГУЛИРОВАНИЯ В ОСОБЫХ ЭКОНОМИЧЕСКИХ ЗОНАХ И ІТ-КЛАСТЕРАХ КАК ЭЛЕМЕНТ РАЗВИТИЯ ЦИФРОВИЗАЦИИ ${ }^{1}$}

\begin{abstract}
В статье проводится исследование существующих тенденщий в иифровом развитии особых экономических зон и цифровых кластеров. Происходящчие сейчас ITтрансформачии способствуют появлению новых типов особых экономических зон - создаются не только высокотехнологичные зоны и цифрровые кластеры, но и спечииализированные зоны развития робототехники, а также цифрровые зоны свободной торговли, являюшиеся симбиозом физической и виртуальной особой зоны, что способствует развитию конкурентного фискального регулирования в IT-секторе разных стран. Особенностью данных территорий является концентрация приоритетных высокотехнологичных направлений, используюших передовые IT-технологии - информационные инноваиии, биотехнологии, новые технологии материалов, роботизацию, а также развитие онлайн-среды. Автор систематизирует созданные иифровые экономические зоны в исследуемых странах, а также условия вхождения в парки высоких технологий и платформы электронных услуг. Выявлено, что для всех крупнейших особых экономических зон и кластеров в IT-сфере общим является предоставление налоговых преференций в отношении инвестиций в цифровые технологии и человеческий капитал (вычеты по расходам на обучение сотрудников, льготы при налогообложении доходов высококвалифицированных сотрудников), а также оказание государственной поддержки НИОКР. Рассмотрены особенности введения преференций для компаний и проектов, функиионирующих в рамках данных территорий, в зависимости от присвоенного квалификачионного статуса.

Ключевые слова: особые экономические зоны, налоговые преференции, ITкластеры, высокотехнологичные зоны, ичифровые зоны свободной торговли.
\end{abstract}

Особые экономические зоны (ОЭЗ) на протяжении последних лет играют важную роль в привлечении иностранных инвестиций, создании рабочих мест, а также широко используются для запуска промышленных секторов и содействия передаче технологий в национальные экономики. С 1970-х гг. большинство зон было создано в развивающихся странах, так, по оценкам Международной организации труда, в 1986 г. функционировало 47 ОЭЗ в 130 странах, в 1995 г. их число составило 500 ОЭЗ, к 2006 г. - до 3500 ОЭЗ в 130 странах. В настоящее время по всему миру насчитывается более 4500 ОЭЗ, которые продолжают распространяться и диверсифицироваться

${ }^{1}$ Статья подготовлена в рамках проекта № 18-08-0014 «Трансформация налогообложения в цифровой экономике» по договору пожертвования денежных средств Фондом целевого капитала ФГАОУ ВПО «Дальневосточный федеральный университет» от 28.01.2019 г. № Д-38-19 и дополнительному соглашению № 1 от 19.03.2019 г. 
под влиянием происходящих в экономике процессов [1, с. 51]. Целью данного исследования является выявление, анализ и обоснование современных трендов в цифровом развитии особых экономических зон. Происходящие в последние годы трансформации особых экономических зон с использованием фискальных инструментов могут стать реальным механизмом цифрового развития, способствующим интернационализации и обеспечению координации между удаленными странами. В большинстве стран наблюдается трансформация от зон экспортной переработки к высокотехнологичным зонам и цифровым кластерам, при этом появляются новые типы экономических зон. Одним из центров подобных изменений является Азиатско-Тихоокеанский регион, цифровизация экономики которого стала причиной трансформаций сектора производства и услуг и способствует расширению существующих отраслей и появлению новых.

Трансформация особых экономических зон в Японии происходит в направлении развития робототехники, биотехнологий и так называемых «отраслей будущего». Первая в мире особая зона развития и тестирования роботов (Special Zone for Robot Development and Testing, Tokku) была создана в 2003 г. в Кюсю. Сегодня в данном направлении активно развивается Азиатская IT-зона (Asia IT special zone) и Fukushima Robot Test Field (RTF, Fukushima Hama-Dori Robot Testing Zone) в провинции Фукусима [2, с. 6].

В Китае сейчас функционирует более 50 национальных зон экономического и технологического развития (National Economic and Technological Development Zones - NETD Zones). В марте 2015 г. в г. Ханчжоу была создана первая в Китае комплексная экспериментальная зона трансграничной электронной коммерции. Развитие комплексной экспериментальной зоны международной электронной коммерции - строительство центров инноваций, сервисов и больших данных, обладающих международной конкурентоспособностью в сфере интернет-торговли, позволило создать оптимальные условия для превращения г. Ханчжоу в стратегический центр на «Цифровом Шелковом пути» (Digital Silk Road). В 2016 . основатель и глава Alibaba Джек Ма впервые предложил концепцию «е-WTP» (электронной мировой торговой платформы), призванной содействовать развитию и объединению среднего, малого и микробизнеса во всем мире, а также стимулировать всемирную торговлю, способствуя экспансии КНР и формируя новые правила глобальной торговли. За 3 года функционирования в Ханчжоу переехали почти 8000 предприятий, занимающихся трансграничной интернет-торговлей, при этом г. Ханчжоу вошел в число китайских городов с самой динамично развивающейся экономикой [3].

Особое внимание уделяет Таиланд созданию так называемых суперкластеров, которые представляют собой географические концентрации отраслей, использующих передовые IT-технологии. Кластеризация особых экономических зон в рамках осуществления Инвестиционной стратегии Таиланда, начавшаяся в сентябре 2015 г., способствовала созданию цифровых кластеров в гг. Чиангмай и Пхукет [4, с. 5]. 
Во Вьетнаме в настоящее время функционируют 3 высокотехнологичных промышленных парка: Парк высоких технологий Хао Лак (в Ханое), Парк высоких технологий Сайгона (в Хошимине) и Парк высоких технологий Дананга (в Дананге). Общие требования к реализуемым в данных парках инвестиционным проектам регулируются налоговым законодательством страны, а также в циркуляре 83/2016 / ТТ-ВТС, при этом для каждой территории предусмотрена конкретная схема стимулирования инвестиций. Инвестиционный проект может быть реализован в рамках парков высоких технологий, если отвечает следующим условиям:

- вид деятельности входит в перечень приоритетных высокотехнологичных направлений (информационные технологии, биотехнологии, новые технологии материалов, технологии автоматизации) в соответствии с декретами 66/2014 / QD-TTg и 13/2017 / QD-TTg;

- затраты на научно-исследовательские работы, выполненные во Вьетнаме в рамках проекта, включают в себя общие расходы на научноисследовательские работы (не менее 5\% годового общего оборота), или расходы на НИОКР (не менее $1 \%$ годового общего оборота);

- численность сотрудников с высшим образованием, которые непосредственно вовлечены в научно-исследовательскую работу проекта, должна составлять не менее 5\% от общей численности персонала проекта;

- производственная деятельность должна быть специализирована и организована с использованием методов автоматизации (не менее трети автоматических устройств управляется по заданным программам);

- система менеджмента качества проекта (компьютеризированная корпоративная система администрирования) соответствует специализированным международным стандартам (например, ISO 9000/2001, CMМ или GMP);

- проект соблюдает экологические стандарты и технические регламенты в своей области деятельности в соответствии с требованиями на международные стандарты (например, ISO 14000) [5, с. 319].

B ноябре 2018 г. Alibaba Group и правительство Руанды заявили об официальном начале проекта Первой мировой электронной торговой платформы (eWTP) в Африке [6].

В России в сентябре 2018 г. китайский интернет-гигант Alibaba Group, оператор связи «Мегафон», Mail.ru Group и Российский фонд прямых инвестиций (РФПИ) в рамках Восточно-экономического форума договорились о создании совместной компании - AliExpress Russia, цель которой развивать трансграничные и местные торговые онлайн-площадки.

Опыт мультимедийного супер-коридора Малайзии (MSC Malaysia) является одним из примеров реализации успешных проектов в IT-секторе. Особая экономическая зона MSC Malaysia, которая существует с 1996 г. в центрально-южной части штата Селангор, внесла значительный вклад в развитие не только цифровой экономики Малайзии, но и ее ВВП в целом [7, с. 9]. В 2017 г. в Малайзии с целью содействия развитию IT-технологий запущены Малайзийский цифровой центр и при содействии Alibaba первая в мире цифровая зона свободной торговли (DFTZ) [8, с. 153]. 
На рис. 1 представлена динамика количества резидентов MSC Malaysia за период 1997-2015 гг., при этом 75\% компаний принадлежит гражданам Малайзии. В 2015 г. экспорт компаний-резидентов составил 38\% общего объема продаж MSC Malaysia [9, с. 7].

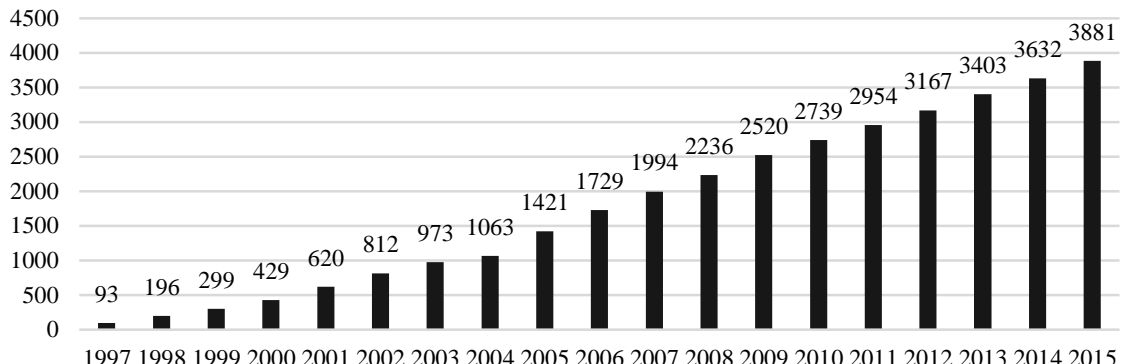

Рис. 1. Количество компаний-резидентов MSC Malaysia (ед.)

$(1997-2015$ гг.)

Катализаторы развивающейся экосистемы цифровых инноваций MSC Malaysia: Аналитика больших данных (Big Data Analytics - BDA), Интернет вещей (the Internet of Things - IoT), электронная коммерция (ECommerce), 6 центров обработки данных (Data Centre \& Cloud) и система обеспечения кибербезопасности.

OЭ3 MSC Malaysia присваивает резидентам - местным и иностранным компаниям IT-сферы разные квалификационные статусы и предоставляет привлекательные преференции, способствующие их развитию. Структура резидентов ОЭ3 MSC Malaysia, представленная на рис. 2, позволяет реализовать комплексный подход к развитию высокодоходной цифровой экономики, основанной на знаниях и призванной обеспечить кадровый потенциал. В структуре резидентов ОЭ3 MSC Malaysia большую часть занимают высокотехнологичные компании, 4\% - инкубаторы и институты высшего образования, $13 \%$ - стартапы [10].

Вне зависимости от квалификационного статуса все резиденты особой экономической зоны MSC Malaysia приобретают право на получение налоговых льгот, а именно предоставление Pioneer Status (100\%-ное освобождение от налогов) на срок до 10 лет или инвестиционного налогового вычета сроком до 5 лет, а также право на полное освобождение от таможенных пошлин на импорт мультимедийного оборудования. Для резидентов, имеющих статус стартапов, дополнительно предусмотрено освобождение от подоходного налога в размере $70 \%$ в течение 5 лет. По состоянию на 2018 г. благодаря 3241 компании IT-сектора, функционирующих в ОЭЗ MSC Malaysia, было создано более 167 тысяч рабочих мест, при этом объем выручки составил 11,2 млрд долл. [11]. Динамичное развитие ОЭЗ MSC Malaysia и ее влияние на IT-сектор Малайзии является одним из факторов, позволивших стране занять 4-е место в рейтинге эффективности из 59 экономик мира. 


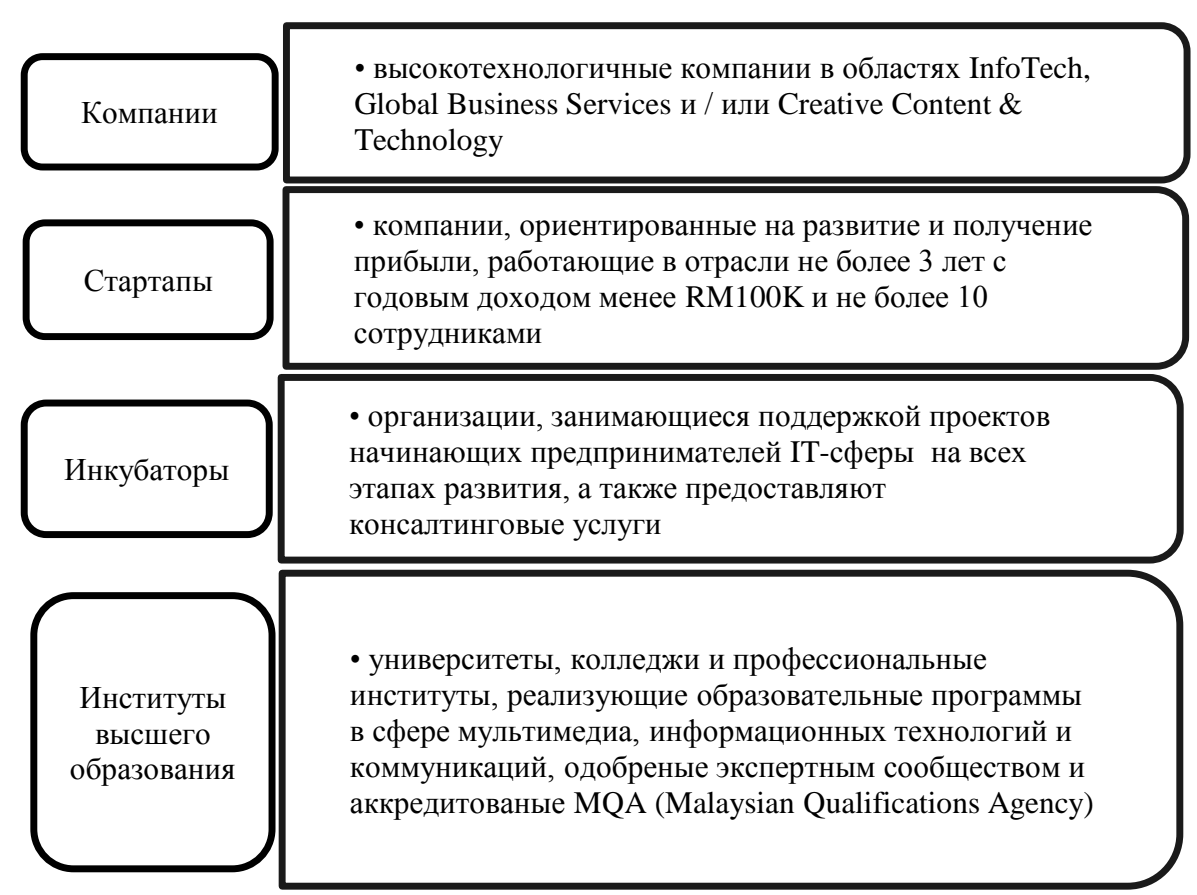

Рис. 2. Структура резидентов MSC Malaysia

В ноябре 2017 г. в Малайзии была создана первая в мире цифровая зона свободной торговли (Digital Free Trade Zone, DFTZ) [11]. Проект был запущен в партнерстве с Alibaba Group в рамках дорожной карты правительства Малайзии, введенной в 2016 г. и направленной на удвоение к 2020 г. в стране объема рынка электронной коммерции. Цель проекта - объединить в глобальном масштабе компании малого и среднего бизнеса Малайзии на базе электронных платформ международной торговли (Alibaba) и содействовать трансграничной торговле и координации между странами в рамках инициативы «Один пояс и один путь».

Цифровая зона свободной торговли направлена на развитие электронной коммерции и увеличение экспорта продукции местных предприятий. Согласно проведенной в Малайзии экономической переписи 2016 г. 43460 субъектов малого бизнеса занимается электронной коммерцией, но лишь 5,9\% их доходов от электронной торговли получены благодаря международным транзакциям. В 2017 г. девять из десяти компаний в Малайзии являлись субъектами малого бизнеса, из которых $28 \%$ присутствовали в Интернете и только $15 \%$ из них использовали Интернет для содействия экспорту. В начале 2018 г. на платформах электронной коммерции в DFTZ представлено уже более 4000 малайзийских малых и средних компаний.

DFTZ является симбиозом физической и виртуальной особой зоны и включает 3 ключевых элемента функционирования, обеспечивающих быструю доставку товаров клиентам (рис. 3) [10]. 


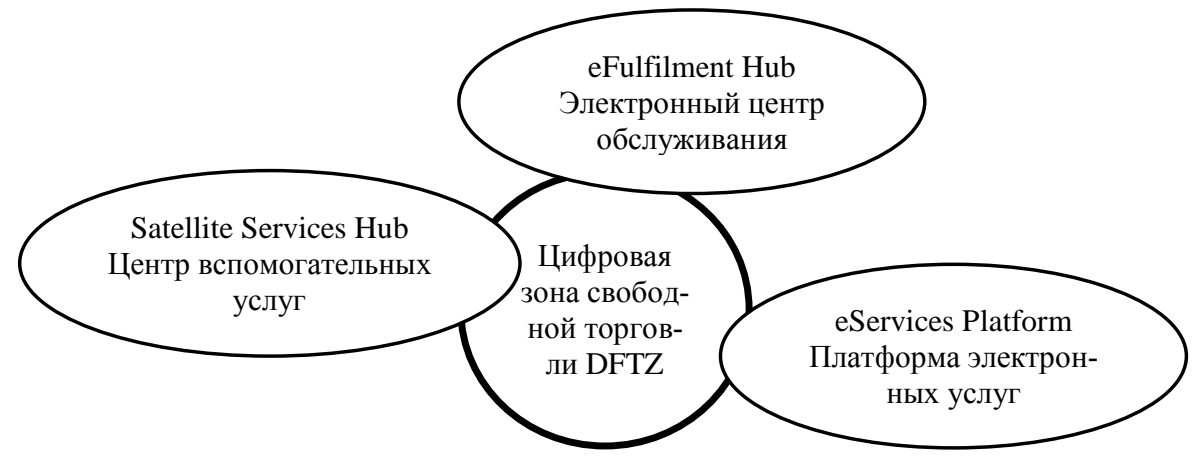

Рис. 3. Ключевые элементы функционирования цифровой зоны свободной торговли

Электронный центр обслуживания (eFulfilment Hub), расположенный вблизи Kuala Lumpur Internet City Aeropolis (KLIA), применяя новейшие автоматизированные технологии сортировки и комплектации, организует хранение до момента онлайн-заказа и логистику после, включая процесс комплектования, упаковки и доставки. Центр разработан как централизованный авиационный, авиагрузовой и логистический объект для Малайзии и региона АСЕАН с целью ускорения экспортных таможенных процедур.

Центр вспомогательных услуг (Satellite Services Hub) содействует организации и предоставлению резидентам дополнительных услуг, связанных с трансграничной торговлей, в том числе финансирование, страхование, сетевое взаимодействие, консалтинг и т.д. Центр расположен в г. КуалаЛумпур и включает в себя автономные онлайн-салоны, учебные центры и открытые пространства для начинающих онлайн-предпринимателей.

Платформа электронных услуг (eServices Platform) предоставляет цифровые услуги, позволяющие эффективно управлять оформлением грузов и другими процессами, необходимыми для трансграничной торговли, включая консультации по карантину, разрешениям и трансграничной торговле. Кроме того, DFTZ помогает адаптировать экспортную деятельность компаний под требования целевых экспортных рынков. За первые полгода функционирования eServices Platform срок оформления грузов на воздушном терминале KLIA сократился с 6 до 3 часов.

Одной из ключевых преференций является традиционная для зон свободной торговли беспошлинная зона, в которую товары могут ввозиться беспошлинно для дальнейшей переработки или для реэкспорта. При этом отличие DFTZ от традиционной зоны свободной торговли состоит в оцифровке торговли и создание инфраструктуры для обслуживания субъектов малого и среднего бизнеса. Товары, приобретенные в Интернете и ввозимые любым лицом через международные аэропорты в Малайзии (KLIA, Пенанг, Сенай, Кота-Кинабалу, Кучинг и Субанг), освобождаются в DFTZ от налога на добавленную стоимость, если сумма покупки (за исключением сигарет, табака и алкоголя) не превышает RM500. При вывозе товаров за пределы DFTZ резиденты должны уплатить НДС. 
Сейчас в Китае функционирует более 50 национальных зон экономического и технологического развития (National Economic and Technological Development Zones - NETD Zones), преференции в которых зависят от политики конкретной зоны и в основном предоставляются на местном уровне и включают в себя: льготные условия предоставления земельных участков или объектов недвижимости, финансирование инновационных IT-проектов, субсидии на привлечение талантливых кадров в области научных и технологических инноваций и др.

Развитие информационных кластеров сегодня становится неотъемлемой частью политики инновационного технологического развития стран. Одним из самых известных и успешных примеров является Силиконовая долина, которая сегодня получает треть всех венчурных инвестиций в США и является родиной многих всемирно известных компаний отрасли - Intel, Apple, Cisco, Yahoo, еВау и др. [12].

Одним из крупнейших китайских ІТ-кластеров стал Пекинский научный парк «Чжунгуаньцунь», в состав которого входят 97 инновационных инкубаторов, 29 университетских научно-технологических парков, 26 инкубационных платформ для сопутствующих направлений [13].

Индийской «кремниевой долиной» является г. Бангалор в регионе Карнатака, IT-кластер которого занимает 4-е место в рейтинге крупнейших мировых технологических кластеров. В рамках 3 особых экономических зон кластера Карнатака функционирует более 3500 IT-компаний с ежегодным доходом более 32 млрд долл. США. Кластер, являясь одним из лидеров экспорта программного обеспечения, за 2016-2017 гг. обеспечил 18\% общего объема экспорта Индии, что составило 82 млрд долл. США [14]. Подобные показатели обеспечены в том числе благодаря налоговым каникулам, предоставляемым экспортерам в ОЭЗ Индии на срок 15 лет: в течение первых 5 лет происходит 100\%-ное освобождение экспортной прибыли, последующие 10 лет - 50\%-ное [15].

«Кремниевый остров» есть и у Японии - остров Кюсю, который создавался с 1970-х гг. для развития полупроводниковой промышленности, в том числе солнечных батарей [16]. Кластер Кюсю с принятием «Робота стратегии Японии» был преобразован в один из мировых центров робототехники и производства промышленных роботов (Yaskawa Electric Corporation) [2].

В России процесс создания центров кластерного развития как эффективного механизма привлечения прямых иностранных инвестиций и интеграции российских кластеров в мировой рынок высокотехнологичной продукции начался в 2012 г. [17]. По данным Российской кластерной обсерватории, в настоящее время в России насчитывается 11 кластеров, специализирующихся на информационно-коммуникационных технологиях [18]. Помимо информационно-коммуникационных кластеров, в России существуют такие территории IT-развития, как инновационный центр «Сколково», Иннополис и с 2018 г. инновационные научнотехнологические центры (ИНТЦ) [19]. 
Для получения налоговых преференций компаниям, осуществляющим деятельность в сфере информационных технологий в России, необходимо пройти государственную аккредитацию в Министерстве связи и массовых коммуникаций РФ [20] и удовлетворять следующим условиям (п. 6 ст. 259, п. 5 ст. 427 НК РФ) [21]:

1) доходы от деятельности в области информационных технологий должны составлять не менее $90 \%$ всех доходов организации (доходы, полученные от иностранных лиц, - не менее 70\%);

2) среднесписочная численность работников для использования льготного порядка признания расходов на электронно-вычислительную технику (ЭВТ) должна составлять не менее 50 человек, а для применения пониженных тарифов страховых взносов - не менее 7 человек.

В РФ компании, осуществляющие бизнес в области информационных технологий, исследовательские корпоративные центры по проекту «Сколково», а также участники проектов в инновационных научно-технологических центрах имеют право на получение следующих преференций:

1) освобождение от начисления амортизации на ЭВТ, и возможность учитывать расходы на ее приобретение единовременно (п. 6 ст. 259 НК РФ);

2) уплачивать страховые взносы, применяя пониженные тарифы (пп. 3 п. 1 ст. 427 НК РФ) [21]. На переходный период до 2024 г. установлены пониженные тарифы страховых взносов: на обязательное пенсионное страхование $(8,0 \%)$, на обязательное медицинское страхование $(4,0 \%)$, на обязательное социальное страхование на случай временной нетрудоспособности и в связи с материнством $(2,0 \%)$ или $1,8 \%$ - с выплат иностранным гражданам (лицам без гражданства), временно пребывающим в РФ (кроме высококвалифицированных специалистов)

Для исследовательских корпоративных центров по проекту «Сколково» применяются пониженные тарифы страховых взносов на обязательное пенсионное страхование - в размере $14 \%$, на обязательное социальное страхование на случай временной нетрудоспособности и в связи с материнством, на обязательное медицинское страхование - 0\% (п. 10 ст. 427 НК РФ). Льготный тариф применяется в течение 10 лет со дня получения статуса участника проекта. Ограничением для данного тарифа является совокупный размер прибыли участника проекта «Сколково» свыше 300 млн руб.

Участники инновационного центра «Сколково», исследовательские корпоративные центры [22] и организации, ведущие научнотехнологическую деятельность в ИНТЦ [19], имеют право на получение освобождений от уплаты следующих налогов:

- НДС в течение 10 лет со дня получения статуса участника проекта;

- налога на прибыль организаций в течение 10 лет со дня получения стату$\mathrm{ca}$, до достижения годового объема полученной от реализации товаров, работ, услуг, имущественных прав выручки в размере 1 млрд руб. (п. п. 1, 2 ст. 246.1 НК РФ). Кроме того, до 2022 г. имеют право применять нулевую ставку исследовательские корпоративные центры, у которых доходы от реализации 
взаимозависимым лицам товаров (работ, услуг), от передачи имущественных прав составят менее $50 \%$ в общей сумме доходов;

- налога на имущество для организаций, признаваемых управляющими компаниями в соответствии с Федеральным законом от 28.09.2010 № 244Ф3 «Об инновационном центре «Сколково», и организаций, получивших статус участника проекта в соответствии с Федеральным законом от 29 июля 2017 г. № 216-Ф3 «Об инновационных научно-технологических центрах и о внесении изменений в отдельные законодательные акты Российской Федерации» (п. 19 и 28 ст. 381 НК РФ);

- земельного налога (в отношении земельных участков, входящих в состав территории инновационного центра «Сколково» или расположенных на территории ИНТЦ) (п. 10 и 13 ст. 395).

Аналогичный порядок предоставления налоговых преференций для компаний IT-сферы действует в Индии. IT-компании вне зависимости от размера и формы собственности могут получить освобождение от уплаты налогов на 5 или 10 лет - при условии, что компания зарегистрирована в технопарке. При этом компании, работающие в IT-сфере, независимо от размера и формы собственности имеют право до 31.03.2020 г. на получение налогового вычета в размере 200\% расходов на НИОКР в рамках проекта [15, с. 56].

В КНР ставка корпоративного налога для любых зарегистрированных высокотехнологичных компаний составляет 15\% (при основной ставке $25 \%$ ) [23]. Кроме того, для компаний, функционирующих в IT-сфере в KHP, вне зависимости от наличия статуса резидента в NETDZ, предусмотрен ряд налоговых преференций. Компании, функционирующие в сфере научно-технологических инноваций, для получения налоговых преференций должны иметь статус технологически развитой сервисной компании (Technologically Advanced Service Company - TASC) или статус предприятия высоких и новых технологий (High and New Technology Enterprise HNTE). Статус TASC или HNTE, кроме пониженной ставки по корпоративному налогу, предусматривает налоговые вычеты в размере $150 \%$ фактически осуществленных в течение года расходов на НИОКР. С 2017 г. технологически развитые сервисные компании дополнительно получили право на применение ставки 0\% по НДС в отношении офшорного аутсорсинга, а также вычета для целей налогообложения прибыли по расходам на обучение работников в размере до 8\% от фонда заработной платы (по сравнению с нормативом до 2,5\% для обычных компаний).

Предприятия высоких и новых технологий, созданные в одной из пяти особых экономических зон или в новом районе Шанхай Пудун, имеют право на налоговые каникулы с первого года получения дохода в виде двухлетнего освобождения по корпоративному налогу. IT-компаниям малого и среднего бизнеса в КНР предоставляется так называемый «супервычет по расходам на НИОКР» - налоговый вычет в размере $175 \%$ фактически осуществленных в течение года расходов на НИОКР [5, с. 57-67].

Право на получение преференций в IT-сфере во Вьетнаме имеют следующие компании: 
- высокотехнологичные инкубаторы, высокотехнологичные компании, венчурные инвестиции для развития высоких технологий;

- компании, применяющие высокие технологии или зарегистрированные в особых экономических зонах, высокотехнологичных парках, включая IT-кластеры, созданные по решению премьер-министра и включенные в список приоритетных проектов страны. Налоговые льготы по корпоративному налогу, предоставляемые компаниям в сфере высоких технологий во Вьетнаме, зависят от периода функционирования компании и приведены на рис. 4 [5, с. 319-329].

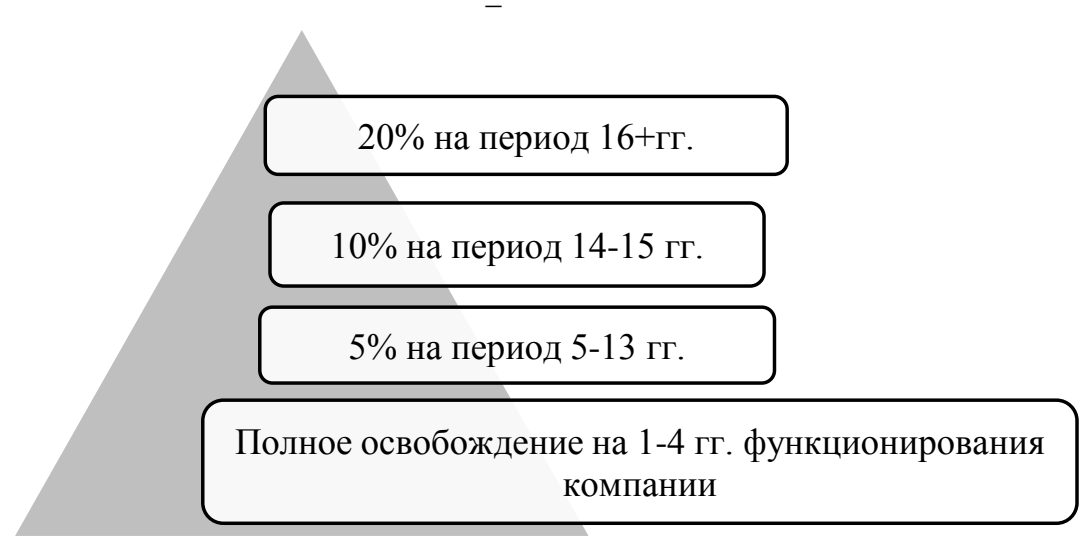

Рис. 4. Налоговые льготы по корпоративному налогу, предоставляемые компаниям в сфере высоких технологий во Вьетнаме

Кроме того, применение пониженной станки по корпоративному налогу в размере 10\% может быть продлено на срок до 30 лет для следующих инвестиционных проектов:

- стоимостью не менее 4000 млрд донгов, задействованных в Парке высоких технологий Хоа Лак;

- стоимостью не менее 3000 млрд донгов, задействованных в Парке высоких технологий Дананга.

Кроме того, компаниям для создания основных средств инвестиционного проекта предоставляются преференции по импортным таможенным пошлинам в течение 5 лет на сырье, материалы и комплектующие, которые не производятся внутри страны. Дополнительно компании получают право на освобождение от налога на землепользование, а также льготные условия аренды земли в рамках конкретного парка высоких технологий.

Компании, занимающиеся исследованиями и разработками на Филиппинах, для получения преференций должны осуществлять деятельность в IT-парке или особой экономической зоне, а также пройти регистрацию в Philippine Economic Zone Authority (PEZA). В соответствии с Законом Республики № 7916 или Законом об особых экономических зонах 1995 г., компаниям предоставляются налоговые каникулы, после окончания кото- 
рых предусмотрена возможность уплачивать специальный налог на валовой доход в размере 5\%, заменяющий все национальные и местные налоги. Также предусмотрено освобождение от таможенных пошлин импортного оборудования или материалов, дополнительный вычет в размере $50 \%$ расходов на обучение и др. [5, с. 203-209].

Таким образом, в зависимости от национальных или локальных приоритетов для развития IT-технологий и IT-кластеров страны по всему миру развивают широкий спектр ОЭЗ. Происходящие сейчас IT-трансформации способствуют появлению новых типов особых экономических зон - создаются не только высокотехнологичные зоны и цифровые кластеры, но и специализированные зоны развития робототехники, а также цифровые зоны свободной торговли, являющиеся симбиозом физической и виртуальной особой зоны, что способствует развитию конкурентного фискального регулирования в IT-секторе разных стран. Особенностью данных территорий является концентрация приоритетных высокотехнологичных направлений, использующих передовые IT-технологии - информационные инновации, биотехнологии, новые технологии материалов, роботизацию, а также развитие онлайн-среды. Проведенное исследование механизмов регулирования выявило, что для всех крупнейших особых экономических зон и кластеров в IT-сфере характерным является предоставление налоговых преференций в отношении инвестиций в цифровые технологии и человеческий капитал (вычеты по расходам на обучение сотрудников, льготы при налогообложении доходов высококвалифицированных сотрудников), а также оказание государственной поддержки НИОКР. Кроме того, характерной особенностью является введение преференций для компаний и проектов, функционирующих в рамках данных территорий, в зависимости от присвоенного квалификационного статуса.

Направления дальнейших исследований - разработка универсального подхода к оценке эффективности налоговых льгот в рамках особых экономических зон в IT-сфере.

\section{Литература}

1. World Investment Report. UNCTAD. 2018. 213 p. ISBN: 978-92-1-112926-7. URL: https://unctad.org/en/PublicationsLibrary/wir2018_en.pdf (accessed: 12 Jan 2019).

2. Japan's New Robot Strategy. Ministry of Economy, Trade and Industry (METI). Government of Japan. April 2018. 27 p. URL: https://www.djw.de/ja/assets/ me$\mathrm{dia} /$ Veranstaltungen/Symposium,\%20MGV/duesseldorf-20180416/djw-symposiumduesseldorf-16.04.2018-kurihara-meti.pdf (accessed: 10 Jan 2019).

3. Концепиия «еWTP» превратит Ханчжоу в центр «Интерактивного Шелкового пути». 2018-02-06 // Портал «Один пояс - один путь». URL: https://rus.yidaiyilu.gov.cn/business/economy/47249.htm (дата обращения: 15.01.2019).

4. Thailand Moving Ahead with Cluster Development. Thailand Board of Investment. Bangkok. BOI. 2015. 7 p. URL: https://www.boi.go.th/upload/content/BOI-brochurecluster\%20area-EN-20151116_53354.pdf (accessed: 10 Jan 2019).

5. Worldwide R\&D Incentives. Reference Guide. Ernst \& Young Global Limited. 2018. 412 p. URL: https://www.ey.com/Publication/vwLUAssets/ey-2018-worldwide-rd-incentives- 
reference-guide/\$FILE/ey-2018-worldwide-rd-incentives-reference-guide.pdf (accessed: 15 Jan 2019).

6. Tasamba J. Rwanda, Alibaba launch Africa's first eWTP. 01.11.2018. URL: http://www.chinadaily.com.cn/a/201811/01/WS5bdaac92a310eff303285f9e.html (accessed: 11 Jan 2019).

7. Gholami R., Lee S., Heshmati A. The causal relationship between ICT and FDI». UNUWIDER. United Nations University (UNU). Research Paper 2005/26. 21 p. URL: https://www.wider.unu.edu/sites/default/files/rp2005-26.pdf (accessed: 11 Jan 2019).

8. Economic Outlook for Southeast Asia, China and India 2018: Fostering Growth Through Digitalisation, OECD Publishing, Paris, 236 p. URL: https://www.oecd.org/dev/ SAEO2018_Preliminary_version.pdf. (accessed: 15 Jan 2019).

9. Malaysia Annual Industry Report. MSC Malaysia. 2015. 35 p. URL: https://www.mdec.my/assets/migrated/pdf/2015-MSC-Malaysia-Annual-Industry-Reportfinal.pdf (accessed: 15 Jan 2019).

10. Eligibility criteria for MSC Malasia status. Malaysian Digital Economy Corporation (MDEC). URL: https://mdec.my/msc-malaysia/qualifying-criteria (accessed: 15 Jan 2019).

11. Tham Siew Yean, The Digital Free Trade Zone (DFTZ): Putting Malaysia's SMEs onto the Digital Silk Road. 2018 № 17. 9 p. (26.03.2018). ISSN 2335-6677. URL: https://www.iseas.edu.sg/images/pdf/ISEAS_Perspective_2018_17@50.pdf (accessed: 10 Jan 2019).

12. Особые экономические зоны. Зарубежный и отечественный опыт / под ред. И.А. Майбурова, Ю.Б. Иванова. М. : ЮНИТИ-ДАНА, 2017. С. 59-68.

13. Zhongguancun Science Park. URL: http://en.zpark.com.cn (accessed: 10 Jan 2019).

14. The Karnataka Industrial Areas Development Board. 2018. URL: http://kiadb.in (accessed: 15 Jan 2019).

15. Tax \& Regulatory laws of India. April 2018. 74 p. URL: https://static.investindia.gov.in/s3fs-public/inline-files/Taxation\%20Toolkit_1.pdf (accessed: 15 Jan 2019).

16. Kyushu-Silicon Island. 2018. URL: http://www.kyuden.co.jp/en_investq_industries_ silicon.html (accessed: 10 Jan 2019).

17. Об утверждении Стратегии инновационного развития Российской Федерации на период до 2020 года: распоряжение Правительства РФ от 08.12.2011 № 2227-р (ред. от 18.10.2018) // КонсультантПлюс: справ.-правовая система.

18. Карта кластеров России: Российская кластерная обсерватория. 2019. URL: http://map.cluster.hse.ru/ (accessed: 15 Jan 2019).

19. Об инновационных научно-технологических центрах и о внесении изменений в отдельные законодательные акты Российской Федерации: федеральный закон от 29.07.2017 № 216-Ф3 (ред. от 04.06.2018) // КонсультантПлюс: справ.-правовая система.

20. O государственной аккредитации организаций, осуществляющих деятельность в области информационных технологий: Постановление Правительства РФ от 06.11.2007 № 758 (ред. от 28.09.2015) // КонсультантПлюс: справ.-правовая система.

21. Налоговый кодекс Российской Федерации (часть вторая): федеральный закон от 05.08.2000 № 117-Ф3 (ред. от 11.10.2018) // КонсультантПлюс: справ.-правовая система.

22. Об инновационном центре «Сколково»: федеральный закон от 28.09.2010 № 244Ф3 (ред. от 29.12.2017) // КонсультантПлюс: справ.-правовая система.

23. Overview of PRC Taxation System. China Corporate Tax. PwC. 2018. URL: https://www.pwccn.com/en/services/tax/accounting-and-payroll/overview-of-prc-taxationsystem.html (accessed: 15 Jan 2019).

The Application of Regulatory Mechanisms in Special Economic Zones and It Clusters as an Element of Digitalization Development

Vestnik Tomskogo gosudarstvennogo universiteta. Ekonomika - Tomsk State University Journal of Economics. 2019. 46. pp. 251-264.

DOI: $10.17223 / 19988648 / 46 / 17$ 
Olga A. Sinenko, Far Eastern Federal University (Vladivostok, Russian Federation). E-mail: sinenko.oa@dvfu.ru

Keywords: special economic zones, tax preferences, IT clusters, high-tech zones, digital free trade zones.

The article analyzes the current trends in the digital development of special economic zones and digital clusters. The ongoing IT transformations contribute to the emergence of new types of special economic zones - high-tech zones and digital clusters, specialized robotics development zones, as well as digital free trade zones that are a symbiosis of the physical and virtual special zones. These processes contribute to the development of competitive fiscal regulation in the IT sector of different countries. A special feature of these territories is the concentration of high-tech priority areas that use advanced IT technologies - informational innovations, biotechnologies, new materials technologies, robotization and online environment development. The author systematizes the established digital economic zones in the countries under study and conditions for entering into high-tech parks and electronic services platforms. It has been revealed that, for all the largest special economic zones and clusters in the IT sphere, it is common to provide tax preferences for investments in digital technologies and in human capital (deductions for employee training expenses, benefits for taxing incomes of highly skilled employees) and R\&D support. The features of the introduction of preferences for companies and projects operating within these territories depending on the assigned qualification status are considered.

\section{References}

1. UNCTAD. (2018) World Investment Report. [Online] Available from: https://unctad.org/en/PublicationsLibrary/wir2018_en.pdf. (Accessed: 12.01.2019).

2. Djw.de. (2018) Japan's New Robot Strategy. Ministry of Economy, Trade and Industry (METI). Government of Japan. April 2018. [Online] Available from: https://www.djw.de/ja/ assets/media/Veranstaltungen/Symposium,\%20MGV/duesseldorf-20180416/djw-symposiumduesseldorf-16.04.2018-kurihara-meti.pdf. (Accessed: 10.01.2019).

3. Odin poyas - odin put'. (2018) Kontseptsiya "eWTP" prevratit Khanchzhou v tsentr "Interaktivnogo Shelkovogo puti" [The eWTP concept will turn Hangzhou into an Interactive Silk Road center]. 6 February. [Online] Available from: https://rus.yidaiyilu.gov.cn/ business/economy/47249.htm. (Accessed: 15.01.2019).

4. BOI. (2015) Thailand Moving Ahead with Cluster Development. Bangkok: Thailand Board of Investment. [Online] Available from: https://www.boi.go.th/upload/content/BOIbrochure-cluster\%20area-EN-20151116_53354.pdf. (Accessed: 10.01.2019).

5. Ernst \& Young Global Limited. (2018) Worldwide R\&D Incentives. Reference Guide. [Online] Available from: https:/www.ey.com/Publication/vwLUAssets/ey-2018-worldwiderd-incentives-reference-guide/\$FILE/ey-2018-worldwide-rd-incentives-reference-guide.pdf. (Accessed: 15.01.2019).

6. Tasamba, J. (2018) Rwanda, Alibaba launch Africa's first eWTP. 01 November. [Online] Available from: http://www.chinadaily.com.cn/a/201811/01/WS5bdaac92a 310eff303285f9e.html. (Accessed: 11.01.2019).

7. Gholami, R., Lee, S. \& Heshmati, A. (2005) The causal relationship between ICT and FDI". UNU-WIDER. United Nations University (UNU). Research Paper 2005/26. [Online] Available from: https://www.wider.unu.edu/sites/default/files/rp2005-26.pdf. (Accessed: 11.01.2019).

8. OECD. (2018) Economic Outlook for Southeast Asia, China and India 2018: Fostering Growth Through Digitalisation. Paris: OECD Publishing. [Online] Available from: https://www.oecd.org/dev/ SAEO2018_Preliminary_version.pdf. (Accessed: 15.01.2019). 
9. MSC Malaysia. (2015) Malaysia Annual Industry Report. [Online] Available from: https://www.mdec.my/assets/migrated/pdf/2015-MSC-Malaysia-Annual-Industry-Reportfinal.pdf. (Accessed: 15.01.2019).

10. Malaysian Digital Economy Corporation (MDEC). (n.d.) Eligibility criteria for MSC Malasia status. [Online] Available from: https://mdec.my/msc-malaysia/qualifying-criteria. (Accessed: 15.01.2019).

11. Tham Siew Yean. (2018) The Digital Free Trade Zone (DFTZ): Putting Malaysia's SMEs onto the Digital Silk Road. [Online] Available from: https:/www.iseas.edu.sg/images/ pdf/ISEAS_Perspective_2018_17@50.pdf. (Accessed: 10.01.2019).

12. Mayburov, I.A. \& Ivanov, Yu.B. (eds) (2017) Osobye ekonomicheskie zony. Zarubezhnyy $i$ otechestvennyy opyt [Special economic zones. Foreign and Russian experience]. Moscow: YuNITI-DANA. pp. 59-68.

13. Zhongguancun Science Park. [Online] Available from: http://en.zpark.com.cn. (Accessed: 10.01.2019).

14. Kiadb.in. (2018) The Karnataka Industrial Areas Development Board. [Online] Available from: http://kiadb.in. (Accessed: 15.01.2019).

15. India. (2018) Tax \& Regulatory laws of India. April. [Online] Available from: https://static.invest-india.gov.in/s3fs-public/inline-files/Taxation\%20Toolkit_1.pdf. (Accessed: 15.01.2019).

16. Kyushu-Silicon Island. [Online] Available from: http://www.kyuden.co.jp/ en_investq_industries_silicon.html. (Accessed: 10.01.2019).

17. Russian Federation. (2018) On approval of the Innovation Development Strategy of the Russian Federation for the period until 2020: Order of the Government of the Russian Federation No. 2227-r of December 8, 2011 (as amended on October 18, 2018). Moscow: Konsul'tantPlyus. (In Russian).

18. Russian Cluster Observatory. (2019) Karta klasterov Rossii [Map of Russian clusters]. [Online] Available from: http://map.cluster.hse.ru/. (Accessed: 15.01.2019).

19. Russian Federation. (2018) On innovative scientific and technological centers and on amendments to certain legislative acts of the Russian Federation: Federal Law No. 216-FZ of July 29, 2017 (as amended on June 4, 2018). Moscow: Konsul'tantPlyus. (In Russian).

20. Russian Federation. (2015) On state accreditation of organizations operating in the field of information technology: Order of the Government of the Russian Federation No. 758 of November 6, 2007 (as amended on September 28, 2015). Moscow: Konsul'tantPlyus. (In Russian).

21. Russian Federation. (2018) Tax Code of the Russian Federation (Part Two): Federal Law No. 117-FZ of 05.08.2000 (as amended on 11.10.2018). Moscow: Konsul'tantPlyus. (In Russian).

22. Russian Federation. (2017) On the Skolkovo Innovation Center: Federal Law No. 244FZ of September 28, 2010 (as amended on December 29, 2017). Moscow: Konsul'tantPlyus. (In Russian).

23. PwC. (2018) Overview of PRC Taxation System. China Corporate Tax. [Online] Available from: https://www.pwccn.com/en/services/tax/accounting-and-payroll/overview-ofprc-taxation-system.html. (Accessed: 15.01.2019). 